\section{Maternal nutrition: how is Eastern and Southern Africa faring and what needs to be done?}

Salam Rehana $A^{1}$, Syed Bushra ${ }^{1}$, Syed Sadia ${ }^{1}$, Das Jai K ${ }^{1}$, Zagre Noel M², Rayco-Solon $\mathrm{P}^{2}$, Bhutta Zulfiqar $\mathrm{A}^{1,3}$

1. Center of Excellence in Woman and Child Health, Aga Khan University, Karachi, Pakistan

2. UNICEF Regional Office for East and Southern Africa, Nairobi, Kenya

3. Center for Global Child Health, Hospital for Sick Children, Toronto

\section{Abstract}

Background: The progress in key maternal health indicators in the Eastern and Southern Africa Region (ESAR) over the

Objective: This paper analyzed available information on nutrition programs and nutrition-specific interventions targeting Objective: This paper analyzed available information on nutrition programs and nutrition-specific
maternal nutrition in the ESAR and proposes steps to improve maternal nutrition in this region.

maternal nutrition in the ESAR and proposes steps to improve maternal nutrition in this region.
Methods: Search was conducted in relevant databases. Meta-analysis was done where there was sufficient data, while data Methods: Search was conducted in relevant databases. Meta-analysis was done where there was sufficient data, while data
from the nutrition programs was abstracted for objectives, settings, beneficiaries, stakeholders, impact of interventions and barriers encountered during implementation.

Results: Findings from our review suggest that multiple nutrition programs are in place in the ESAR; including programs that directly address nutrition indicators and those that integrate corresponding sectors like agriculture, health, education, and water and sanitation. However, their scale and depth differ considerably. These programs have been implemented by a and the private sector in the region. Most of these programs are clustered in a few countries like Kenya, Uganda and Ethiopia while others e.g. Comoros, Somalia and Swaziland have only had a limited number of initiatives.

Conclusion: These programs have been associated with some improvements in overall maternal health and nutritional indicators; however these are insufficient to significantly contribute to the progress in the region. Efforts should be prioritized in countries with the greatest burden of maternal undernutrition and associated risk factors with a focus on existing promising interventions to improve maternal nutrition.

Keywords: Maternal nutrition, Eastern and Southern Africa, undernutrition

DOI: http://dx.doi.org/10.4314/ahs.v15i2.28

Introduction Nutrition status of mother, both undernutrition (body morbidity and mortality and are also associated with mass index $(\mathrm{BMI})<18.5 \mathrm{~kg} / \mathrm{m} 2)^{2}$ ) and overweight (BMI long-term, irreversible cognitive, motor and health im$>25 \mathrm{~kg} / \mathrm{m}^{2}$ ), are intricately linked to pregnancy out- pairments ${ }^{2-5}$. Likewise, short maternal stature, often a comes and later on infant and child nutrition and health ${ }^{1}$. result of childhood stunting in girls, is a significant risk Maternal malnutrition is a key contributor to poor fe- factor for obstructed labour and caesarean delivery. On tal growth, intrauterine growth restriction (IUGR) and the other hand, maternal overweight and obesity are asconsequent low birth weight (LBW). These can in turn sociated with excess maternal morbidity, preterm birth and increased infant mortality ${ }^{3}$ as well as increased risk of childhood obesity continuing into adolescence and early adulthood ${ }^{5}$.

Corresponding author: Bhutta Zulfiqar A

Founding Director,

Center of Excellence in

Women and Child Health,

Aga Khan University,

Karachi- 74800, Pakistan

Email: zulfiqar.bhutta@aku.edu Besides malnutrition, maternal infections especially malaria and HIV/AIDS also contribute majorly towards maternal undernutrition and adverse pregnancy outcomes. According to the global burden of diseases 2010, child and maternal undernutrition risk factors including maternal micronutrient deficiencies, suboptimal past two decades has been slow. diverse range of players including respective government ministries, international agencies, non government organisation breastfeeding and childhood underweight are collective- ly accountable for almost $7 \%$ of the global disease burden $^{6}$ contributing to at least a fifth of maternal deaths along with the increased probability of poor pregnancy outcomes? These are most prevalent in the regions of South East Asia, South America and Africa, with some countries in Eastern and Southern Africa Region (ESAR) having maternal undernutrition prevalence rate as high as $35 \% \%^{8}$. Despite the declining trend over the past few decades, the prevalence of low BMI $(<18.5$ $\mathrm{kg} / \mathrm{m}^{2}$ ) among women of reproductive age (WRA) in Africa and Asia still looms higher than $10^{1} \%^{1}$. The eastern, northern and western African regions have shown some improvements; however in southern Africa the

\section{Figure 1: Countries in the UNICEF ESAR}

\section{Eastern and Southern Africa}

Eastern and Southern Africa is a vast, geographically diverse region that stretches from the Red Sea in the north to the Cape of Good Hope. Er in the south. Since its independence on 9 July 2011, South Sudan has become the newest member in the region.

Reaional overviow

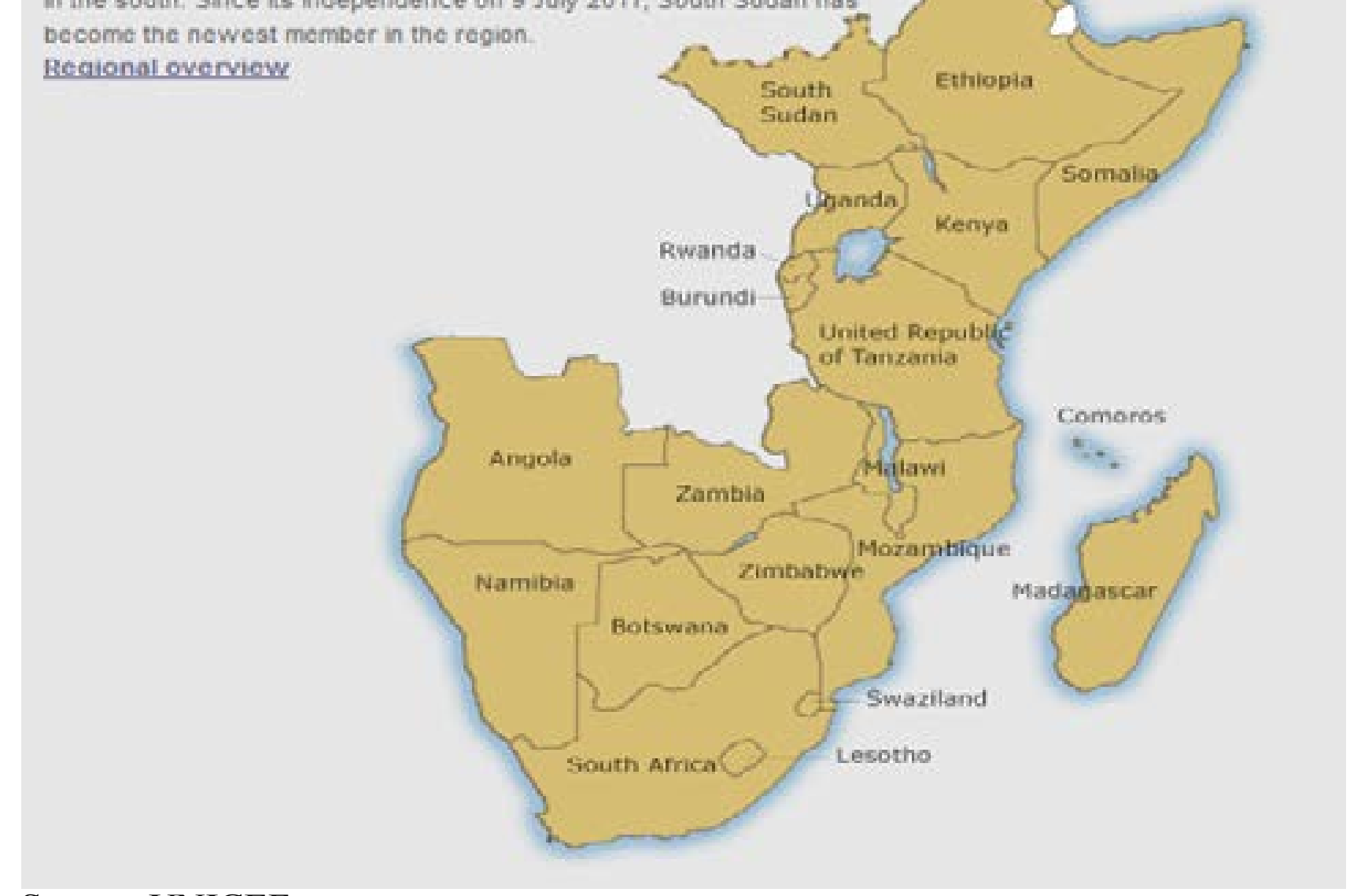

Source: UNICEF

situation has not improved or might have even worsSimultaneously, prevalence of overweight (BMI $\geq 25 \mathrm{~kg} / \mathrm{m}^{2}$ ) and obesity (BMI $\geq 30 \mathrm{~kg} / \mathrm{m}^{2}$ ) among ing in all regions of the wold an reached more than $30 \%$ and $10 \%$ globally and in Africa espectively ${ }^{1}$.

Maternal nutrition in Eastern and Southern Africa: ESAR stretches from the Red Sea in the north to the Cape of good hope in the south encompassing 21 countries specific to United nations international chilen's emergency fund (UNICEF) and takes into account only developing countries where a UNICEF office is deemed relevant (Figure 1).

\begin{tabular}{|l|l|l|}
\hline \multicolumn{2}{|c|}{ EASTERN } & SOUTHERN \\
\hline Burundi & Mauritius & Botswana \\
Comoros & Mozambique & Lesotho \\
Djibouti & Rwanda & Namibia \\
Eritrea & Somalia & South Africa \\
Ethiopia & Tanzania & Swaziland \\
Kenya & Uganda & \\
Madagascar & Zambia & \\
Malawi & Zimbabwe & \\
\hline
\end{tabular}

African Health Sciences Vol 15 Issue 2, June 2015 
Most countries in the region belong to the group of ceptive prevalence (36.5\%), family planning need satislower income countries while Angola, Lesotho and faction (48.7\%), intermittent preventive treatment for Swaziland are among the middle-income countries and malaria in pregnant women (IPTp) (28.3\%), postnatal Botswana, Namibia and South Africa among the upper care (32.5\%), iron/folic acid supplementation (53.2\%), middle income group?. These middle income countries antenatal care (ANC) (1 visit: $82 \%, 4$ visits: $51.5 \%$ ) and in southern Africa are amongst the countries with the skilled attendance at delivery $(55.9 \%)$ also remain low highest gross national income, however, severe income There are wide disparities across the extreme equity inequalities exist in the middle income group countries as well.

The progress in key maternal health indicators over the past two decades has been painfully slow in the ESAR; with merely $1 \%$ reduction in maternal anemis and a deline in cline in maternal mortality from 638 to 409 per 100,000
live births. The available data from the recent demographic health surveys (DHS) and multiple indicator cluster surveys (MICS) for ESAR countries suggests high prevalence of both undernutrition (BMI $<18.5$ $\left.\mathrm{kg} / \mathrm{m}^{2}\right)$ and overweight $\left(\mathrm{BMI} \geq 25 \mathrm{~kg} / \mathrm{m}^{2}\right)$ at $14 \%$ and $15 \%$ respectively with a prevalence of undernutrition as high as $40 \%$ in some countries like Eritrea. Recent analysis reveals that globally, Africa has the highest proportion of pregnant women with iron deficiency anemia (haemoglobin $<110 \mathrm{~g} / \mathrm{L}$ ) at $20.3 \%$ and vitamin

A deficiency (serum retinol $<0.70 \mu \mathrm{mol} / \mathrm{L}$ ) at $14.3 \%{ }^{1}$. Coverage rates for the evidence based interventions for maternal health across the life cycle including contrastrata and coverage for contraceptive prevalence, ANC (at least 1 visit) and skilled delivery are well below $40 \%$ for the poorest quintiles of the population.

We undertook this review to assess available information on nutrition programs in the region and systematically review the data from studies focusing on nutritional interventions aimed at improving maternal nutrition in the ESAR countries. Our review was guided by conceptual framework based on various interventions to improve maternal nutrition status either directly or indirectly (Figure 2). Nutrition specific interventions or programs include micronutrient supplementation, food fortification, food distribution, nutrition education and counseling, disease prevention and control including deworming, malaria and HIV; while nutrition sensitive interventions or programs include; agricultural interventions, water sanitation and hygiene (WASH) interventions, reproductive health and women empower ment and social protection.

\section{Figure 2: Conceptual Framework}

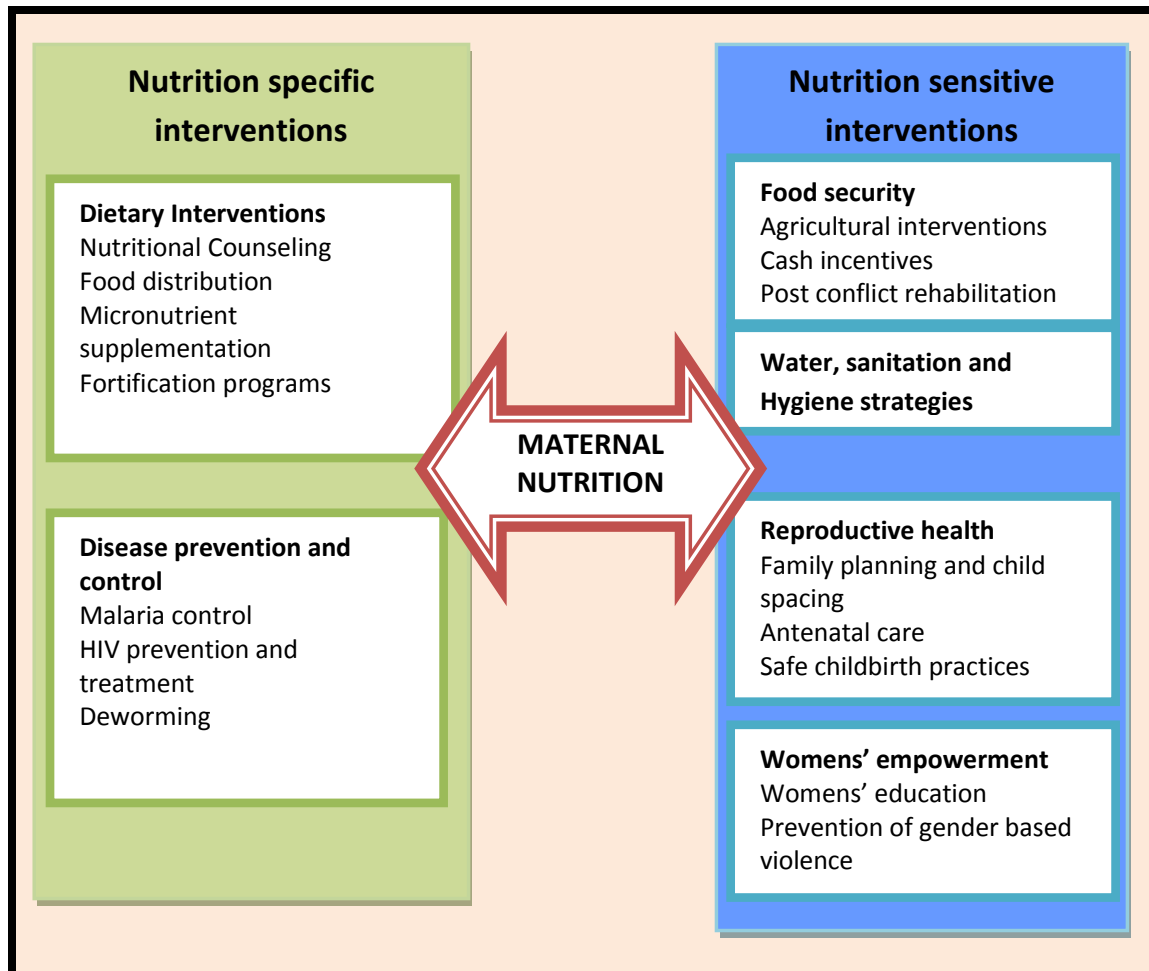

Methods

for continuous variables with respective $95 \%$ confi-

We searched electronic databases including Pubmed, Google Scholar, the Cochrane library, Popline, LILACS, CINAHL, EMBASE, Ministry of Health websites of respective countries, ELDIS, GREYLit, Partnerships for Health Reform, IDEAS, WHO, WFP, UNICEF and the World Bank databases up to March 2013 to identify relevant programs and interventions aimed at improving nutrition among WRA in the ESAR countries. All indexed publications including trials, quasi studies and pre-post evaluations were also identified and relevan papers were selected for abstraction. Hand search was done through the reference lists of the existing reviews and meta-analyses to identify relevant papers from the region.

We performed both qualitative and quantitative analysis for the included papers. Meta-analysis was done where there was sufficient data to do so, while qualitative analysis was done for all the identified papers. Data for program objectives, settings, beneficiaries, stakeholders, impact of interventions and barriers encountered during implementation was abstracted from the included programs. Indexed papers for the meta-analysis were abstracted for study design, study setting, target population, allocation concealment, blinding, randomization, generalizability of the intervention(s) and outcomes of interest. All the data was recorded in a standardized abstraction table. Two reviewers were responsible for data abstraction and any discrepancies found were resolved with consultation from the third reviewer.

Data extracted from articles included for meta-analysis was pooled and the results were expressed as relative risks (RR) for discrete data and mean difference (MD)
(GIV)

method was used to calculate pooled estimates for dis-

crete outcomes. Assessment of statistical heterogeneity was done by using $\mathrm{p}$ values and $\mathrm{I}^{2}$ values and a $\mathrm{p}$ value of $<0.05$ and $\mathrm{I}^{2}$ of $>30 \%$ was indicative of high heterogeneity and in these instances, cause was sought and a random effects model was used. All analyses were performed using Review Manage 5.2.

\section{Results}

report the findings from the nutrition specific and sensitive programs and meta-analysis separately below: Findings from the nutrition programs:

Most of the programs in the ESAR were focused on agricultural interventions followed by the interventions to prevent and manage infection (including HIV/AIDS and malaria), family planning and reproductive health A substantial number of large scale programs were also found on food fortification and food provision along with post-crisis rehabilitation. There were programs on financial incentives, nutrition education, micronutrient supplementation, gender based violence prevention and very few on substance abuse. Most of these programs were implemented in collaborations with the respective government ministries and international agencies whereby the agencies provided support via funding or technical assistance, while governments were responsible for the implementation. Some of the programs were completely assisted by the international agencies alone or in partnership with the for-profit private sector. A few programs were solely run by government or through the support from NGOs. Figures $3 \mathrm{a}$ and $3 \mathrm{~b}$ hows the distribution of programs in the ESAR countries. 


\section{Figure 3a: Large Scale Nutrition Specific Programs in ESAR countries}

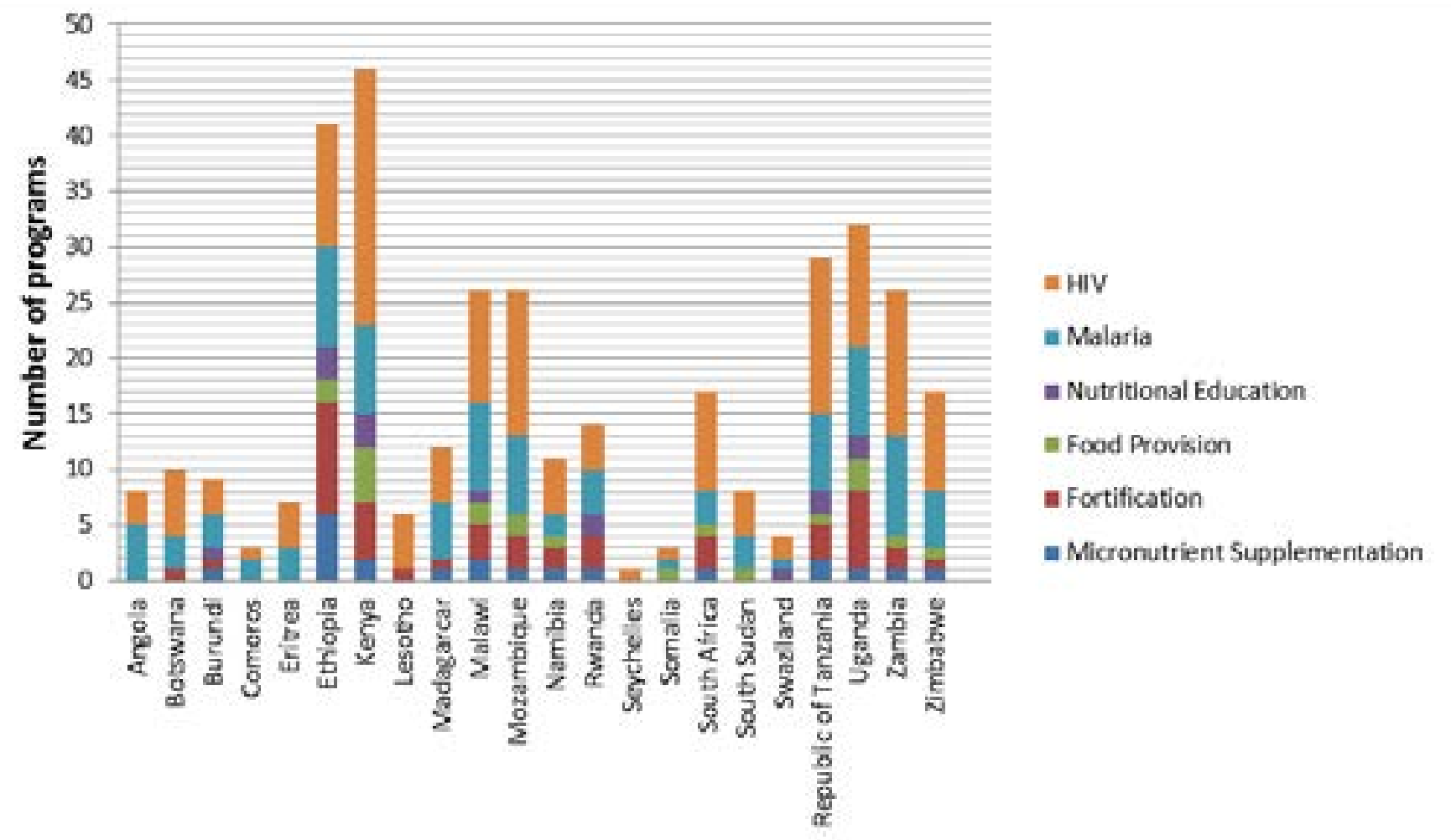

Figure 3b: Nutrition Sensitive Programs in ESAR countries

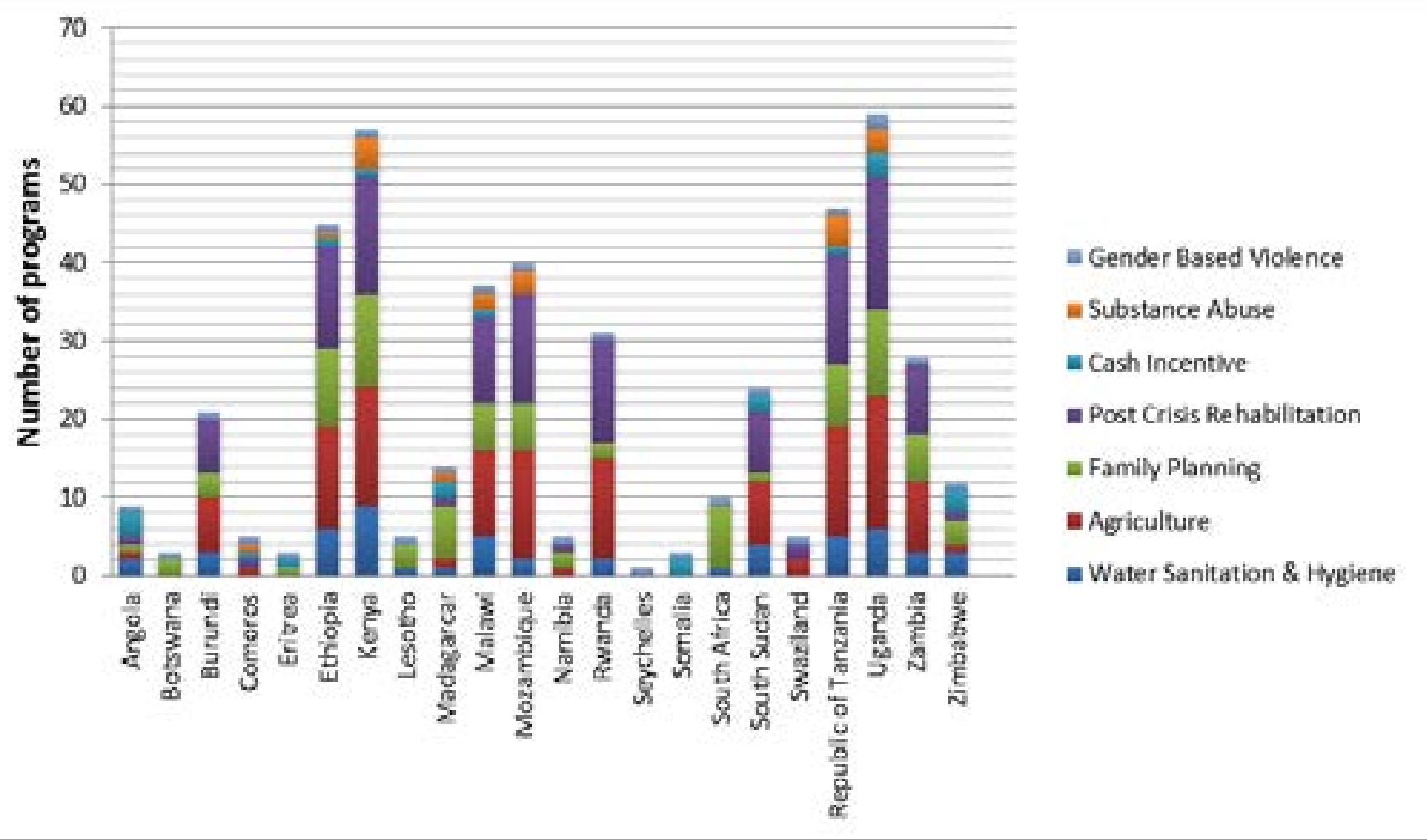

Nutrition specific programs: Programs aimed at di- opia, Kenya, and Uganda while Swaziland and Comoros rectly improving nutrition status included micronutrient had relatively fewer numbers of micronutrient supplesupplementation, food fortification and prevention and mentation and food fortification programs. Most of the management of infections like malaria and HIV/AIDS. supplementation and fortification programs focused A greater number of such programs were seen in Ethi- on nutrition specific objectives while infection control programs majorly focused on prevention and management and lacked nutrition specific evaluations; however, some of these infection control programs included micronutrient supplementation as a part of the package.

Micronutrient supplementation programs especially iron/folic acid supplementation for pregnant women have led to increased coverage and compliance with a resultant decline in anemia among pregnant women and WRA ${ }^{10}$. National level data indicates that in the year 2008 , Kenya had a $69 \%$ coverage for maternal iron/ folic acid supplementation, while the coverage in Malawi and Zambia were $76 \%$ and $84 \%$ respectively ${ }^{11}$. For some countries like Ethiopia, despite a large number of existing micronutrient supplementation programs, the coverage remains low $(17 \% \text { in } 2008)^{11}$, perhaps suggesting more targeted delivery of the interventions. Maternal anemia rates in these countries have also shown declining trends as in Kenya as it has declined from $54 \%$ in 1990 to $34 \%$ in 2012; and similar trends have been seen in Uganda (a decrease from $49 \%$ to $33 \%$ ) and Ethiopia (decline from $37 \%$ to $22 \%$ ) during the same time period ${ }^{12}$. However Swaziland achieved a minor decline of about $6 \%$ during the same period, reflecting a need for more attention in some countries ${ }^{12}$.

In 2002, the health ministries of ESAR countries passed a resolution to initiate and promote food fortification initiative which was subsequently launched in 2004. Based on the latest data available by flour fortification initiative (FFI), four countries have mandatory iron fortification in wheat and maize i.e. Kenya, Rwanda, South Africa and Uganda ${ }^{13}$. The activities of the fortification projects are directed towards producing enhanced quality of food available to the public. Universal salt iodization program has proved to be a great success in sustainable elimination of iodine deficiency. Countries such as Burundi (98\%), Kenya (98\%), Rwanda (99\%), Uganda $(96 \%)$ and Zimbabwe (94\%) have greatly benefited from salt iodization and achieved almost universal coverage for households consuming adequately iodized salt (15 parts per million or more) in $2012^{14}$.

Other countries in the region reporting an encouraging coverage in 2012 include; Comoros (82\%), Lesoth $(84 \%)$, Botswana $(95 \%)$ and Namibia $(63 \%)$, howeve much has to be done for countries such as Djibouti, Ethiopia and Somalia that currently have very low coverage for salt iodization ${ }^{14}$. Some programs have also used iron fortified bread as well as vitamin A fortified cooking oil $1^{15}$ and surveillance data have reported decrease in neural tube defects due to folate fortification ${ }^{16}$. Moreover there has been a steady increase in the number of African countries since 2002 that have passed legislature to make food fortification of commoditie such as flour mandatory or at least voluntary ${ }^{17}$. More recently bio-fortification programs have been seen in the region whereby food enriched with vitamin A, Vitamin $\mathrm{B}$ complex, zinc, iron and folic acid are being produced 18-22. There has been an increase in the initiatives of food fortification and coverage of a few like salt iodization has improved significantly in a few countries, but there is lack of evidence whether the quality was sufficient and met the standards desired for such a strategy to make maximal impact.

Infection control programs mainly involved malaria and HIV/AIDS preventive and control measures. Malaria control programs in the region comprise of free distribution of insecticides treated nets (ITNs), redeemable coupons/vouchers for ITNs, insecticide spraying, IPTp and environmental vector control measures ${ }^{23,24}$. These programs have led to an increased ITN ownership and usage and have also led to substantial improvements in IPTp coverage to above $90 \%$ in countries like Tanzania, Uganda, Kenya, Zambia, Malawi, Ethiopia and Mozambique; followed by $69 \%$ and $63 \%$ for Zambia and Tanzania in $2012^{7}$. However these coverage rates are still inadequate to meet the endemic burden of malaria for some countries in the region like Somalia and Swaziland where the coverage still remained $1 \%$ and $9.9 \%$ respectively in $2012^{7}$. Various HIV/AIDS targeted programs have been launched and have varied in the interventions and services delivered ranging from policy making, HIV prevention and treatment, monitoring and evaluation of HIV/AIDS services, nutrition in HIV to providing support to orphans and vulnerable children (OVC) affected by HIV/AIDS. These programs have significantly increased HIV testing during pregnancy and have led to an increase in the number of women having access to HIV testing and getting antiretroviral therapy (ART) ${ }^{25}$. HIV prevention programs have also led to a decrease in risky sexual behaviors as well as an increase in number of people reporting condom use in their last sexual encounter

HIV incidence has dramatically reduced from 2001 to 2011 by $41 \%$ in South Africa, by $73 \%$ in Malawi by $71 \%$ in Botswana, by $68 \%$ in Namibia, by $58 \%$ in Zambia, by 50\% in Zimbabwe and by 37\% in Swaziland 
which has the highest HIV prevalence in the world ${ }^{26,27}$. Ethiopia achieved a $90 \%$ reduction in the rate of new HIV infections in the last decade. However, countrie such as Tanzania, Kenya, Mozambique and Uganda currently still have some of the highest HIV prevalence rate in the $\mathrm{ESAR}^{26}$ reflecting the need for more programs in these countries. The coverage of effective antiretroviral regimens in low- middle- income countries for preventing mother to child transmission (MTCT) is $57 \%$ in 2011 , and still a lot is desired to eliminate it completely. A recent report suggests that on average, nearly half of all children newly infected with HIV in the 20 countries of Africa surveyed were acquiring HIV during breastfeeding, due to low antiretroviral coverage during this period. Although in 2012, 375,000 more pregnant women living with HIV received antiretroviral medicines than in $2009^{27,28}$. Three countries in the region (Botswana, Namibia and Rwanda) have attained universal access to ART, which is achieving more than $80 \%$ coverage, while Botswana, Namibia and Zambia have further met their goal of providing antiretroviral
medicines to $90 \%$ of the potential women in $2012^{25}$.

Nutrition sensitive programs: Among the programs that broadly addressed nutrition, a large number of programs involved family planning and reproductive health initiatives that led to an increase in knowledge and contraception prevalence rate along with increasing number of women completing at least three antenatal visits during pregnancy and institutional deliveries ${ }^{29-31}$. Kenya, Tanzania and Uganda have successfully mproved the number of pregnant women receiving at least 1 antenatal visit at $92 \%, 94 \%$ and $88 \%$ respectively in $2012^{7}$. However the contraception prevalence in some countries stays disappointing; with Kenya, Swaziland and Ethiopia having a current contraceptive prevalence rate of $46 \%, 65 \%$ and $29 \%$ respectively 2012 .

Africa lags behind on the WASH measures as safe drinking water was available to $66 \%$ of the population in 2010, which has increased from $61 \%$ in 2000 and has a wide equity gap (urban: $85 \%$ and rural $54 \%$ ), while population having access to improved sanitation facility is $40 \%$ in 2010, up from 37\% in 2000 (urban: 54\% and rural: $31 \%)^{7}$. The programs to improve WASH measures included rehabilitation or construction of new water points and wells along with protection from ground water pollution, provision of piped water to house- olds, community mobilization and training to empowertat the target population to maintain the newly constricted or rehabilitated water infrastructure. Sanitation was improved by the construction of latrines in various settings; within households, schools as well as public plac es. New sewage disposal and treatment plants were feature of a small number of the programs.

Hygiene was improved by rural community education sessions, which entailed information dissemination on hand washing, hygienic food preparation as well as safe waste disposal. Many encouraging results have been reported, such as an increasing number of rural households having access to improved water and sanitation sources as well as having the facility of piped water being delivered to their home ${ }^{32}$. Moreover, a substantial number of community members have been educated on the importance of hygiene, a fact which is represented in the large number of households that have incorporated these practices in their daily routines as a result of the community led total sanitation program (CLTS) ${ }^{33-35}$. But these programs need to be implemented at larger or national scale in order to achieve wider gains. A steady progress has been made in provision of access to safe drinking water in Ethiopia and Malawi reporting 93\% and $84 \%$ access respectively in $2012^{7}$. Uganda and Tanzania have also been making progress, with an encouraging coverage of $70 \%$ and $59 \%$ respectively in $2012^{7}$. However countries such as Kenya, Malawi, Uganda, Somalia and Mozambique require renewed efforts as the coverage is still below the $50 \%$ mark in 2012

Investing in agricultural sector aims to strengthen the economy, foster poverty alleviation, household financia security, food security and food diversity of countries in the ESAR. The interventions employed in these programs include small holder farmer training in the lates farming techniques and technology, irrigation infrastructure rehabilitation, improved seeds and fertilize provision, as well as instituting a loaning system to help small holder farmers to start and sustain their businesses. Another area of focus was to provide farmers with access to markets and equipping them with the tools necessary to be competitive in their trade. Impact of these programs has been multifold in the areas where they were implemented, as evidenced by the increase in the hectors of unused land that has been brought under cultivation as a result of introduction of farmers to new farming techniques, provision of cultivating tools such as tractors, as well as the construction of new irrigation systems ${ }^{36}$. The provision of improved seeds and fertilizers to farmers has resulted in not only a higher yield of cash crops such as cotton, but has also contributed to crop diversity as well as quality, all of which has had a beneficial impact of small holder farmers in the trade market ${ }^{36}$. Moreover the effect on household security was evident in the boost in the monthly income incurred by the farmers ${ }^{37}$. Established in 2003 by the African Union, Comprehensive Africa Agriculture Development Program (CAADP), an African owned initiative to boost agricultural productivity by extending the area under sustainable land management and reliable water control, improving rural infrastructure and trade-related capacities for market access, increased food supply, reducing hunger and improving responses to food emergencies and improving agricultural research, technology dissemination and adoption. National governments have committed to increasing their agricultural investment by at least $10 \%$ of the national budget for average annual growth of 6 per cent in agriculture by 2015. However, most of these programs have reported direct agriculture impact, and does not quite clearly outline impacts on nutrition indicators. Notably, most such programs did not include nutrition impacts as part of the overall objectives.

Implementation barriers: Most of the programs reported administrative barriers in implementation including delays in procurement, lack of communication and coordination between implementing agencies, lack of project monitoring and evaluation, high staff turnover, challenges in obtaining transportation to project area and inability to meet demands of the target popof authorization from local authorities and lack of support from government organizations. The most common financial problem identified was lack of long term financial sustainability and delays in release of funds leading to interruption in service. Environmental issues were mostly related to natural disasters such as floods or droughts leading to delays in product distribution to target population due to physical inaccessibility. A maor setback of these programs is the lack of rigorous evaluation designs and monitoring mechanisms. Most of the nutrition sensitive programs including agricultural programs, WASH strategies, sexual and reproductive health and infection prevention and control, did not include nutrition specific objectives and indicators in the evaluation plan; hence making it more challenging to draw conclusions on their effectiveness on maternal nutrition indicators.

\section{Findings from the Meta-analysis}

We included 39 indexed studies for the systematic review and meta-analysis conducted in ESAR countries; of which 37 were randomized controlled trials while 2 were pre-post intervention studies. 10 studies were conducted in Tanzania, 6 each in Uganda and Kenya, 5 each in Malawi and South Africa, 3 each in Zimbabwe and Mozambique and 1 in Ethiopia. Five studies involved interventions in adolescent girls, aged 12 to 18 years while the rest involved adult pregnant or lactating women. Table 1 summarizes the findings from the systematic review. 


\begin{tabular}{|c|c|}
\hline $\begin{array}{l}\text { Intervention Description } \\
\text { Iron supplementation: } \\
\text { Analysis from five studies comparing daily or } \\
\text { weekly supplementation of ferrous sulfate with a } \\
\text { dose of } 200 \text { to } 400 \mathrm{mg} \text { with no iron } \\
\text { supplementation }\end{array}$ & $\begin{array}{l}\text { Estimates } \\
\begin{array}{l}\text { Significant impacts: } \\
\text { hemoglobin }\end{array}(0.49,95 \% \text { Cr: } 0.25,0.73)\end{array}$ \\
\hline $\begin{array}{l}\text { Vitamin A supplementation: } \\
\text { Five studies evaluated the impact of vitamin A } \\
\text { supplementation with synthetic vitamin A in } \\
\text { doses of } 5000 \text { IU, } 10 \text { o00 IU and } 25000 \text { IU for } \\
\text { pregnant and lactating women. Three of these } \\
\text { studies were done among HIV positive women. }\end{array}$ & $\begin{array}{l}\text { HIV -ve women: Non-significant impacts: Maternal hemoglobin }(-0.01 \text {, } \\
95 \% \text { CI: }-0.19,0.16) \text {, change in maternal hemoglobin }(-0.08,95 \% \text { CI: }-0.35 \text {, } \\
0.18) \\
\text { HIV +ve women:Significant impacts: birth weight }(83.35,95 \% \text { CI: } \\
69.65,97.05) \\
\text { Non-significant impacts: weight at } 6 \text { months }(23.89,95 \% \text { CI: }-111.35 \text {, } \\
159.13) \text {, length at } 6 \text { months }(0.05,95 \% \text { CI: }-0.24,0.34) \text {, anemia at } 1 \text { year } \\
(1.01,95 \% \text { CI: } 0.93,1.10)\end{array}$ \\
\hline $\begin{array}{l}\text { Food products for improving vitamin A status } \\
\text { Two studies evaluated the impact of using fruits, } \\
\text { vegetables and oils including carrots, papayas, } \\
\text { sunflower oil, red palm oil and } \beta \text { carotene to } \\
\text { improve vitamin A status in post partum women. }\end{array}$ & Significant impacts: Serum retinol $(0.20,95 \%$ CI: $0.07,0.33)$ \\
\hline $\begin{array}{l}\text { Multiple micronutrient } \\
\text { supplementation: } \\
\text { MMN supplementation involved supplementation } \\
\text { of pregnant and lactating women with at least } \\
\text { three micronutrients compared to or two or less } \\
\text { micronutrients. Five of the studies were done in a } \\
\text { HIV negative population while the rest were done } \\
\text { in HIV infected women }\end{array}$ & 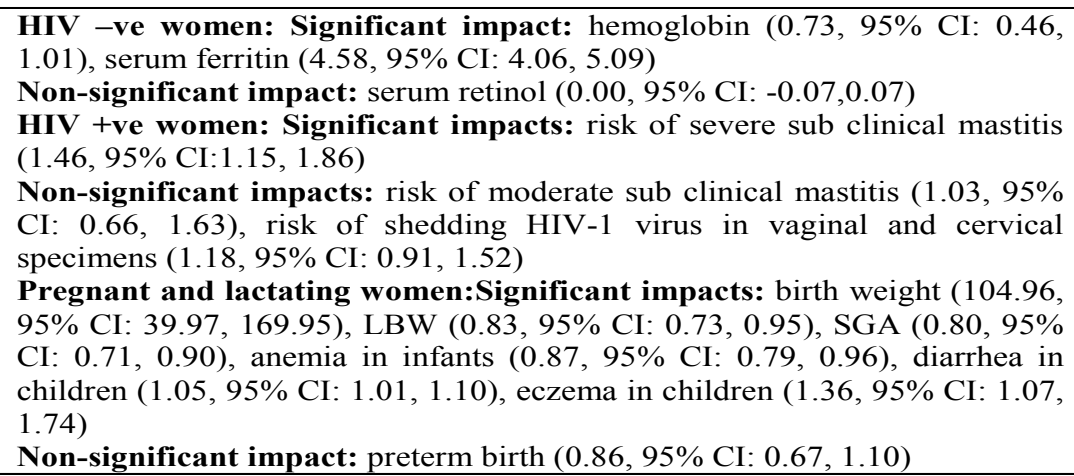 \\
\hline $\begin{array}{l}\text { Macronutrient supplementatio } \\
\text { Data from two studies evaluat } \\
\text { lipid and milk based supplement } \\
\text { HIV positive women for a durati }\end{array}$ & $\begin{array}{l}\text { Non-significant impact: maternal weight at } 6 \text { months post partum }(-0.21 \text {, } \\
95 \% \text { CI: }-1.65,1.22)\end{array}$ \\
\hline $\begin{array}{l}\text { Malaria prevention: } \\
\text { Six studies were included in the analysis, three } \\
\text { focused on multiple dose treatment with } \\
\text { sulfadoxine-pyrimethamine while two studies } \\
\text { focused on the use of INNs in pregnancy and one } \\
\text { study compared both ITN and IPTp use in } \\
\text { pregnancy }\end{array}$ & $\begin{array}{l}\text { IPTp use: Non-significant impacts: Malaria }(1.15,95 \% \text { CI: } 0.40,3.27) \text {, } \\
\text { anemia }(0.75,95 \% \text { CI: } 0.53,1.07) \text {, fetal loss }(0.85,95 \% \text { CI: } 0.52,1.40) \text {, } \\
\text { LBW }(1.17,95 \% \text { CI: } 0.82,1.69) \\
\text { ITN use: Significant impact: Peripheral parasitemia }(0.74,95 \% \text { CI: } 0.56 \text {, } \\
0.97) \\
\text { Non-significant impact: maternal anemia }(0.88,95 \% \text { CI: } 0.75,1.03) \text {, febrile } \\
\text { illness }(0.91,95 \% \text { CI: } 0.68,1.23)\end{array}$ \\
\hline $\begin{array}{l}\text { Deworming: } \\
\text { Five studies evaluated the impact of treating } \\
\text { pregnant women with one or more antihelmenthic } \\
\text { drugs in recommended doses }\end{array}$ & 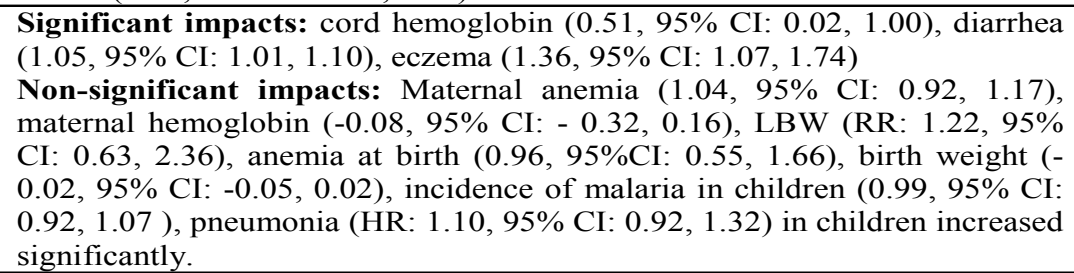 \\
\hline $\begin{array}{l}\text { Interventions to prevent intimate partner } \\
\text { violence: } \\
\text { Two studies evaluated the impact of a } \\
\text { microfinance intervention } \\
\text { women }\end{array}$ & $\begin{array}{l}\text { Significant impacts: women empowerment }(1.41,95 \% \text { CI: } 1.22,1.63) \\
\text { Non-significant impacts: Vulnerability to violence }(0.88,95 \% \text { CI: } 0.50 \text {, } \\
1.54)\end{array}$ \\
\hline
\end{tabular}

Our analysis showed that daily or weekly iron supple- tural interventions by promoting production and use mentation versus no supplementation significantly im- of vitamin A rich sweet potatoes significantly increased proved serum ferritin and hemoglobin among pregnant vitamin A intake from orange sweet potato sources and women $^{38-42}$. Vitamin A supplementation among HIV serum retinol levels ${ }^{50,51}$. Multiple micronutrient supplepositive women during pregnancy significantly im- mentation (MMN) among pregnant and lactating womproved birth weight with non-significant impacts on en significantly improved hemoglobin, serum ferritin, infants' weight and length at 6 months $s^{43-47}$. Using every- birth weight, small-for-gestational age (SGA), anemia in day food items including carrots, papayas, sunflower oil, children with non-significant impact on serum retinol red palm oil and $\beta$ carotene among postpartum women levels and preterm birth ${ }^{52-61}$. Malaria prevention in pregsignificantly increased serum retinol levels ${ }^{48,49}$. Agricul- nancy showed that the use of ITNs in pregnancy sig- nificantly reduced the risk of peripheral parasitemia ${ }^{62-67}$. These findings should be interpreted with caution as limited number of studies were pooled for each intervention due to restricted region and population for inclusion. In addition the studies pooled in the meta-analysis were heterogeneous in terms of dose, duration and follow up period of the intervention. These findings were compared with recent reviews of the global evidence from the Lancet series on maternal child nutrition detailing the effectiveness of nutrition specific interventions to improve maternal nutrition and birth outcomes ${ }^{68}$.

\section{Discussion}

Findings from our review suggest that multiple programs impacting nutrition are in place in the ESAR; including programs that directly address nutrition indicators and those that integrate corresponding sectors like agriculture, health, education, and water and sanitation. However, their scale and depth differ considerably. Nutrition directed programs in the region include micronutrient supplementation, food fortification, direct food provision and prevention and control of infectious diseases including HIV and malaria while broader programs focus majorly on agricultural interventions along with family planning, reproductive health, water and sanitation, reduction of gender-based violence, women's empowerment and cash incentives. These programs have been implemented by a diverse range of players including respective government ministries, international agencies, NGOs and the private sector in the region. Most of these programs are clustered in a few countries like Kenya, Uganda and Ethiopia while others e.g. Comoros, Somalia and Swaziland have only had a limited number of initiatives. During the last couple of years, many programs are being initiated and implemented in the region; however these donot appear in our review since they have started recently and their evaluations are not yet reported.

These programs have been associated with some improvements in overall maternal health and nutritional indicators; however these are insufficient to significantly contribute to the progress in the region. A major short coming is the lack of rigorous evaluation plans and nutrition specific objectives to measure the actual impact on relevant maternal nutrition indicators. $\mathrm{Nu}$ trition sensitive programs like agricultural and financia initiatives supporting women empowerment and even infection control programs may broadly impact maternutrition in the region. However, it is challenging to gauge their contribution towards reduction in maternal undernutrition due to the lack of nutrition specific program objectives and evaluations. Key barriers and bottlenecks identified were the weak health systems, poor governance, limited financial and human resources, limited supplies and competing priorities that pose major barriers towards not only the implementation but also scale-up and sustainability of maternal nutrition programs.

\section{Recommendations}

- Focus should be on existing promising intervention to improve maternal nutrition including simple interventions like periconceptional folic acid supplementation/fortification, maternal balanced energy protein, vitamin $\mathrm{A}$, multiple micronutrient and calcium supplementation, breast feeding promotion, appropriate complementary feeding, preventive zinc supplementation and management of acute malnutrition in children.

- Country specific plans should be devised which should be led by respective governments in collaboration with international agencies and other stakeholders.

- Targeted nutrition specific programs should be prioritized towards the countries with greatest burden of maternal undernutrition in the region including Swaziland, Comoros, Djibouti, Ethiopia and Somalia.

- Countries with highest HIV prevalence rate in the ESAR like Tanzania, Kenya, Mozambique and Ugand should be focused for implementing infection prevention and management programs.

- These interventions need to be properly packaged and delivered at scale through appropriate delivery channels in order to reach the masses.

- Nutrition-sensitive programs in ESAR need to be more nutrition sensitive by explicitly incorporating nutrition issues in the initial design, monitoring and evaluating nutrition impacts with specific/appropriate nutrition indicators and ensuring that there are no unintended negative consequences to nutrition from the programs like inconsistent strategies or duplication of efforts.

Evaluations should follow rigorous study designs and gather high quality data with enhanced estimation methods for reliable outcome measures in order to gauge the actual impact of these intervention packages on maternal nutrition and identify the region specific best buys. 
Concternal nutrition in ESAR is affected by a range of 9. UNICEF. Eastern and Southern Africa: Regional factors including chronic conflicts and emergencies, Overview. Accessed from: http://www.unicef.org/esaic infectious dinines, periodic outbreaks and endemin infectious diseases, rampant poverty and inequities in access and utilization. Political stability and country measures to take maximal impact and guaranteeing long term sustainability. If ensured, this could go a long way in reducing the funding gap and promotion domestic investments, especially from public sector programs. Public private partnership should be enhanced or scaled up at all levels with better coordination between the various stakeholders in order to avoid duplication of effort and promote synergies. With firm commitmen and implementation of evidence based interventions, attention to the region specific contextual factors and transparent monitoring and evaluation, the ESAR region can move a step closer to achieving the goal of reducing maternal undernutrition.

\section{References}

1. Black RE, Victora CG, Walker SP, Bhutta ZA, Christian $\mathrm{P}$, de Onis M, et al. Maternal and child undernutrition and overweight in low-income and middle-income countries. The Lancet. 2013.

2. Abu-Saad K, Fraser D. Maternal nutrition and birth outcomes. Epidemiologic reviews. 2010;32(1):5-25.

3. Kanade AN, Rao S, Kelkar RS, Gupte S. Materna nutrition and birth size among urban affluent and rural women in India. J Am Coll Nutr. 2008 Feb;27(1):137-45. 4. Victora CG, Adair L, Fall C, Hallal PC, Martorell R, Richter L, et al. Maternal and child undernutrition: consequences for adult health and human capital. Lancet 2008 Jan 26:371(9609):340-57

5. Barker DJ, Clark PM. Fetal undernutrition and disease in later life. Rev Reprod. 1997 May;2(2):105-12.

6. Lim SS, Vos T, Flaxman AD, Danaei G, Shibuya K, Adair-Rohani $\mathrm{H}$, et al. A comparative risk assessment of burden of disease and injury attributable to 67 risk factors and risk factor clusters in 21 regions, 1990-2010: a systematic analysis for the Global Burden of Disease Study 2010. The Lancet. 2013;380(9859):2224-60.

7. WHO. Countdown to 2015. Building a Future for Women and Children. The 2012 Report. Available from: www.countdown $2015 \mathrm{mnch}$.org/reports-and-articles/2012-report.

8. UNICEF. A Snapshot of the Nutrition Situation in
Overview. Accessed from: http://www.unicef.org/esa-

10. World Vision. Improving nutrition of women and children: the MICAH program. Available from: http:// www.pdfio.com/site/www.worldvision.ca/.

11. UNICEF. Tracking progress on child and maternal nutrition. 2008

12. WHO. WHO global database on anemia. Last up dated 2007.

3. Flour Fortification Initiative 2013. Available from http://www.ffinetwork.org/global_progress/

14. UNICEF. The State of World's Children 2013 Children with Disabilities. Available from http://www. SWCR2013_ENGLISH.pdf.

15. Elhakim N, Laillou A, El Nakeeb A, Yacoub R, Shehata M. Fortifying baladi bread in Egypt: reaching more than 50 million people through the subsidy program. Food Nutr Bull. 2012 Dec;33(4 Suppl):S260-71.

16. GAIN. GAIN National Food Fortification Program; Available from: http://www.gainhealth.org/programs/gain-national-food-fortification-program.

17. Flour Fortification Initiative. Available from: http:// www.ffinetwork.org/global_progress/index.php. 18. HarvestPlus. Improving nutrition through better staple food crops. Available from: www.eiard.org/... HarvestPlus\% 20-\%20Improving $\% 20$ nutrition $\% 20$ hro.

. Flour Fortification Initiative. Available from: http:// www.ffinetwork.org/.

20. PATH. Sweet Potato Action for Security and Health in Africa Project (MAMA -SASHA). Available from: http://www.path.org/projects/sweetpotato-project. php.

21. World Bank.GAIN National Food Fortification Program. Available from: http://www.worldbank. org/projects/P090137/gain-national-food-fortification-program?lang $=$ en

22. DO B. Social determinants of health: Food fortification to reduce micronutrient deficiency in Uganda. Strengthening the National Food Fortification Programme. Draft background paper.

23. The World Bank. Zambia Malaria Booster Project. Available from: http://www.worldbank.org/projects/ P096131/zambia-malaria-booster-project?lang=en 24. USAID. President's Malaria Initiative Malaria Operational Plan (MOP) Malawi. Available from: pmi.gov/ countries/mops/fy12/malawi_mop_fy12.pdf unicef.org/sowc2013/files/Table_2_Stat_Tables_
25. USAID. The Clinical HIV/AIDS Services strength- ince, Mozambique. Food and nutrition bulletin. 2005 ening project in Sofala, Manica and Tete (CHASS-SMT) Sep;26(3):281-6.

in Mozambique Avalable from: hit://Wwwcha $\mathrm{com} /$

26. The World Bank. World Development Indicators database. Available from: data.worldbank.org/data-catalog/world-development-indicators.

27. UNAIDS World AIDS Day Report, 2012

28. The World Bank. Second Multisectoral STI/ HIV/AIDS Prevention project 2005-2014. Available from: http://www.worldbank.org/projects/P090615/ second-multisectoral-stihivaids-prevention-project?lang=en.

29. Associates A. Scaling Up Family Planning in Zambia. Available from: http://abtassociates.com/PDFS/ Zambia-SUFP-Project-Brief_Final.aspx

30. USAID. Voices from the Village: Improving Lives through CARE's Sexual and Reproductive Health Programs. Going the Extra Mile to Provide and Sustain Family Planning Services in Remote Madagascar. 31. The World Bank. Zimbabwe's Health Results based Financing. Available from: http://web.worldbank. org/external $/$ projects $/$ main?page $\mathrm{PK}=51351038$ \&piP $\mathrm{K}=51351152$ \&theSite $\mathrm{PK}=40941$ \&projid $=\mathrm{P} 125229$.

32. The World Bank. Urban Water Sector Project, Burkina Faso. Available from: http://documents.worldbank. org/curated/en/2013/05/17727672/burkina-faso-urban-water-sector-project-p106909-implementation-status-results-report-sequence- 08 .

33. CLTS Programme, Malawi (2009). Available from http://www.communityledtotalsanitation.org/sites/ communityledtotalsanitation.org/files/Programme Overview_for_Donor_Visit.pdf

34. The World Bank. Sanitation Project Cameroon 2011-2015. Available from: http://www.worldbank org/projects/P117102/sanitation-project?lang=en . 35. Community led Total Sanitation. Available from http://www.communityledtotalsanitation.org/.

36. The World Bank. Emergency Support to Enhance Food Security (ESEFS) Project, Benin. Available from: http://documents.worldbank.org/curated/ en/2012/06/16537457/benin-emergency-support-enhance-food-security-project-benin-emergency-support-enhance-food-security-project.

37. IFDC. The Cassava Plus Project Nigeria. Available from: http://www.ifdc.org/Projects/Recent2/North and_West_Africa_Division/Cassava-Plus/. 38. Horjus P, Aguayo VM, Roley JA, Pene MC, Meershoek SP. School-based iron and folic acid supplementation for adolescent girls: findings from Manica Prov-
39. Haidar J, Umeta M, Kogi-Makau W. Effect of iron women in Addis Ababa, Ethiopia. East African medical journal. $2005 \mathrm{Jul} ; 82(7): 349-52$.

40. Beasley NM, Tomkins AM, Hall A, Lorri W, Kihamia $\mathrm{CM}$, Bundy DA. The impact of weekly iron supplementation on the iron status and growth of adolescent girls in Tanzania. Tropical medicine \& international health: TM \& IH. 2000 Nov;5(11):794-9. $\mathrm{PA}$, ter Kuile FO. The effect of weekly iron and vitamin A supplementation on hemoglobin levels and iron status in adolescent schoolgirls in western Kenya. European journal of clinical nutrition. 2009 Feb;63(2):173-82.

42. Beard JL, Hendricks MK, Perez EM, Murray-Kolb LE, Berg A, Vernon-Feagans L, et al. Maternal iron deficiency anemia affects postpartum emotions and cognition. The Journal of nutrition. $2005 \mathrm{Feb} ; 135(2): 267-72$. 43. van den Broek NR, White SA, Flowers C, Cook JD, Letsky EA, Tanumihardjo SA, et al. Randomised trial of vitamin A supplementation in pregnant women in rural Malawi found to be anaemic on screening by HemoCue. BJOG : an international journal of obstetrics and gynaecology. 2006 May;113(5):569-76.

44. Semba RD, Kumwenda N, Taha TE, Mtimavalye L, Broadhead R, Garrett E, et al. Impact of vitamin A supplementation on anaemia and plasma erythropoietin concentrations in pregnant women: a controlled clinical trial. European journal of haematology. 2001 Jun;66(6):38995.

45. Kumwenda N, Miotti PG, Taha TE, Broadhead R, Biggar RJ, Jackson JB, et al. Antenatal vitamin A supplementation increases birth weight and decreases anemia among infants born to human immunodeficiency virus-infected women in Malawi. Clinical infectious diseases : an official publication of the Infectious Diseases Society of America. 2002 Sep 1;35(5):618-24

46. Villamor E, Saathoff E, Bosch RJ, Hertzmark E, Baylin A, Manji K, et al. Vitamin supplementation of HIV-infected women improves postnatal child growth. The American journal of clinical nutrition. 2005 Apr;81(4):880-8.

47. Fawzi WW, Msamanga GI, Kupka R, Spiegelman D, Villamor E, Mugusi F, et al. Multivitamin supplementation improves hematologic status in HIV-infected women and their children in Tanzania. The American journal of clinical nutrition. 2007 May;85(5):1335-43.

48. Lietz G, Henry CJ, Mulokozi G, Mugyabuso JK, supplementation on serum zinc status of lactating

41. Leenstra T, Kariuki SK, Kurtis JD, Oloo AJ, Kager 
Ballart A, Ndossi GD, et al. Comparison of the effects the hemoglobin concentration of pregnant Tanzanian women. The Journal of mutrition. 2003 May;133(5):1339ternal vitamin A status. The American journal of clinical 46.

mutrition. 2001 Oct;74(4):501-9. 58.

58. Fawzi WW, Msamanga GI, Urassa W, Hertzmark 49. Ncube TN, Greiner T, Malaba LC, Gebre-Medhin E, Petraro P, Willett WC, et al. Vitamins and perinaM. Supplementing lactating women with pureed pa- tal outcomes among HIV-negative women in Tanpaya and grated carrots improved vitamin A status in zania. The New England journal of medicine. 2007 Apr a placebo-controlled trial. The Journal of nutrition. 2001 5;356(14):1423-31.

May;131(5):1497-502

50. Hotz C, Loechl C, Lubowa A, Tumwine JK, Ndeezi $G$, Nandutu Masawi A, et al. Introduction of beta-carotene-rich orange sweet potato in rural Uganda resulted in increased vitamin A intakes among children and women and improved vitamin A status among children. The Journal of nutrition. 2012 Oct;142(10):1871-80.

51. Hotz C, Loechl C, de Brauw A, Eozenou P, Gilligan

$\mathrm{D}$, Moursi $\mathrm{M}$, et al. A large-scale intervention to introduce orange sweet potato in rural Mozambique increases vitamin A intakes among children and women. The British journal of nutrition. 2012 Jul 14;108(1):163-76.

52. McClelland RS, Baeten JM, Overbaugh J, Richardson BA, Mandaliya K, Emery S, et al. Micronutrient supplementation increases genital tract shedding of HIV-1 in women: results of a randomized trial. Journal of acquired immune deficiency syndromes (1999). $2004 \mathrm{Dec}$ 15;37(5):1657-63. Vitamin supplementation increases risk of distribution of sulfadoxine-pyrimethamine for intermitsubclinical mastitis in HIV-infected women. The Journal tent preventive treatment of malaria during pregnancy of nutrition. 2010 Oct;140(10):1788-92. improved coverage but reduced antenatal attendance 54. Gomo E, Filteau SM, Tomkins AM, Ndhlovu P, in southern Malawi. Tropical medicine \& international Michaelsen KF, Friis H. Subclinical mastitis among health:TM \& IH. [Evaluation Studies Multicenter Study HIV-infected and uninfected Zimbabwean women par- Research Support, Non-U S Gov't]. 2009;14(2):183-9. ticipating in a multimicronutrient supplementation trial. 63. Shulman CE, Dorman EK, Cutts F, Kawuondo Transactions of the Royal Society of Tropical Medicine K, Bulmer JN, Peshu N, et al. Intermittent sulphadoxand Hygiene. 2003 Mar-Apr;97(2):212-6.

55. Coutsoudis A, Pillay K, Spooner E, Kuhn L, Coovadia HM. Randomized trial testing the effect of vitamin A supplementation on pregnancy outcomes and early mother-to-child HIV-1 transmission in Durban, South Africa. South African Vitamin A Study Group. AIDS (London, England). 1999 Aug 20;13(12):1517-24. 56. Latham MC, Ash DM, Makola D, Tatala SR, Ndossi GD, Mehansho H. Efficacy trials of a micronutrient dietary supplement in schoolchildren and pregnant women in Tanzania. Food \& Nutrition Bulletin. 2003;24(Supplement 2):120-8.

57. Makola D, Ash DM, Tatala SR, Latham MC, Ndossi G, Mehansho H. A micronutrient-fortified beverage prevents iron deficiency, reduces anemia and improves
66. ter Kuile FO, Terlouw DJ, Phillips-Howard PA, cide-treated bednets and sulfadoxine-pyrimethamine in Hawley WA, Friedman JF, Kariuki SK, et al. Reduction a highly malarious area of Kenya: a randomized conof malaria during pregnancy by permethrin-treated bed trolled trial. Transactions of the Royal Society of Tropnets in an area of intense perennial malaria transmis- ical Medicine and Hygiene. 2003 May-Jun;97(3):277-82. sion in western Kenya. The American journal of tropical 68. Bhutta ZA, Das JK, Rizvi A, Gaffey MF, Walker N, medicine and hygiene. 2003 Apr;68(4 Suppl):50-60. Horton $\mathrm{S}$, et al. Evidence-based interventions for im67. Njagi JK, Magnussen P, Estambale B, Ouma J, Mugo provement of maternal and child nutrition: what can be B. Prevention of anaemia in pregnancy using insecti- done and at what cost? Lancet. 2013 Jun 5. 